\title{
Perancangan Performance Management System Divisi Purchase dengan Balance Score Card Framework dan Strategy MAP (Studi Kasus Rumah Sakit Bersalin X di Pacitan)
}

\author{
Resti P. Ari Widjaja \\ Universitas Airlangga Surabaya \\ e-mail: resti.pawidjaja@gmail.com
}

\begin{abstract}
The business of health services is a business that is closely related to social responsibility because the object is human so that it cannot be equated with other businesses. Hospital as one of the health service facilities, has a role in increasing public awareness of the importance of health. A hospital is a unique and complex organization because it is a labor-intensive institution, has characteristics and functions and functions that are specific to the process of producing medical services and have various professional groups in the service of sufferers. This study aims to design a Performance Management System in order to analyze internal and external factors, facilitate the monitoring and evaluation process to improve the performance and competitive advantage of Rumah Sakit Bersalin X Pacitan as a whole and improve purchase division performance in particular. The research method used in this study is qualitative with purposive sampling for sampling techniques. The results of this study, that management of Rumah Sakit Bersalin X execute High Contacts Business Strategy by means of recruiting workers who have the competence, knowledge, skills and abilities as a core employee business company that cannot be excluded, because this workforce is an executor in the company and is very much needed to be maintained. It can be seen from learning and growth perspective, the companies prefer 'people expertise', by choosing workers who have expertise that is tailored to each division within the company. People expertise is prepared as the executor of the company's strategies and plans that are seen in the internal process. The dominance of these people expertise that drives 'operational excellence' which is expected to increase customer equity and thus will affect the company's overall income and profitability.
\end{abstract}

Keywords: key performance indikator, strategy map, balanced scorecard

\section{PENDAHULUAN}

Keberhasilan sebuah organisasi ataupun perusahaan dalam mencapai visi dan misi sangat tergantung dari kualitas sumber daya manusia yang dimiliki. Kualitas sumber daya manusia tersebut dapat ditunjukkan oleh kompetensi, skills, dan kemampuan karyawan dalam menciptakan kualitas kerja yang professional dalam membangun sebuah teamwork dalam organisasi. Untuk mengetahui bagaimana keefektifan sumber daya manusia dalam organisasi maka perlu dilakukan suatu evaluasi yang dapat digunakan sebagai dasar penilaian kinerja karyawan dan pimpinan dalam usaha mencapai visi dan misi organisasi (Ambarwati, 2002).
Rumah sakit di Indonesia pada awalnya dibangun oleh dua institusi. Pertama adalah pemerintah dengan maksud untuk menyediakan pelayanan kesehatan bagi masyarakat umum terutama yang tidak mampu. Kedua adalah institusi keagamaan yang membangun rumah sakit nirlaba untuk melayani masyarakat miskin dalam rangka penyebaran agamanya (Muluk, 2007). Hal yang menarik saat ini adalah mulai bermunculan rumah sakit swasta yang bersaing dengan rumah sakit pemerintah di mana rumah sakit tersebut juga mengutamakan profit sebagai tujuan dari organisasi. Dengan demikian, kini rumah sakit mulai memainkan peran ganda, yaitu tetap melakukan pelayanan publik sekaligus mem- 
peroleh penghasilan (laba) atas operasionalisasi pelayanan kesehatan yang diberikan kepada masyarakat (Jufrizen dan Radiman, 2010).

Melihat perkembangan dan persaingan global diperlukan perubahan dalam pola pengelolaan manajemen yang berorientasi pada pengguna jasa. Rumah sakit sebagai perusahaan harus berpikir profit tanpa meninggalkan fungsi sosialnya, untuk mencapai sasaran yang dikehendaki dalam usaha mencapai profit, usaha perumahsakitan harus meningkatkan kualitas pelayanannya. Demi peningkatan kualitas pelayanan, harus ada upaya untuk mengetahui harapan dan kebutuhan pelanggan yang beragam (Tjiptono, 2000 dalam Laksono, 2008). Hal ini tidak terkecuali, Klinik Bersalin X di Pacitan yang sudah berubah dan berkembang menjadi sebuah Rumah Sakit Bersalin X pada tahun 2010 di mana investasi, operasional rumah sakit dan gaji pegawai masih menjadi tanggung jawab pemilik perusahaan. Salah satu cara yang dapat dilakukan adalah dengan merencanakan performance management system (manajemen kinerja). Di mana sistem ini diharapkan akan mendukung eksistensi Rumah Sakit Bersalin X melalui monitoring, evaluasi dan management action secara berkelanjutan.

Performance management (manajemen kinerja) merupakan model pendekatan yang bertujuan menumbuhkan budaya prestasi dalam setiap entitas ekonomi dengan menghubungkan atau menyelaraskan tujuan utama dengan yang sekunder (Mwita, 2000). Selama ini hampir mayoritas perusahaan dan Rumah Sakit Bersalin X di Pacitan khususnya melakukan evaluasi kinerja hanya berdasar pada aspek finansial yang diukur dalam setiap semester dan tahunan. Penilaian baik buruknya kinerja perusahaan, sering kali didasarkan atas terpenuhi atau tidaknya target yang direncanakan. Jika target tersebut tidak terpenuhi (di bawah forecast) maka akan diadakan evaluasi aspek finansial/budget yang dihadiri oleh pihak-pihak yang bersangkutan. Kondisi ini memperlihatkan bahwa pengukuran terhadap kinerjanya hanya dari sisi aspek finansial saja (Vanany et al., 2004).

Adanya perubahan lingkungan bisnis yang dinamis dengan kondisi persaingan yang semakin ketat diperlukan tidak hanya aspek finansial tetapi juga aspek non finansial. Oleh karena itu, kebutuhan akan sistem pengukuran kinerja yang terintegrasi (aspek finansial dan non-finansial) menjadi sebuah keharusan bagi perusahaan (Vanany et al., 2004). Mengingat bahwa harapan konsumen dalam bidang kesehatan adalah memperoleh pelayanan kesehatan yang rasional, bermutu, efektif, manusiawi, dan terjangkau maka konsumen akan sangat selektif dalam hal pemilihan jasa rumah sakit. Untuk itu, sebuah rumah sakit dalam menjalankan misinya harus mampu menjalankan usahanya secara efektif dan efisien sehingga misi yang telah ditetapkan tersebut dapat terpenuhi secara seimbang.

Manajemen Rumah Sakit Bersalin X menyadari bahwa salah satu langkah pengelolaan unit usaha yang profesional adalah dengan penetapan strategi perusahaan yang didukung dan diaplikasikan oleh semua jenjang dalam perusahaan serta dapat diukur agar dapat berfungsi secara efektif untuk mencapai visi perusahaan. Untuk itu, diperlukan suatu alat yang dapat mengukur sistem manajemen dan kinerja perusahaan dengan menggunakan framework balance score card dan strategy maps.

Balance scorecard memiliki kemampuan melakukan hal tersebut dengan membagi ukuranukuran ke dalam empat perspektif berbeda yang saling terkait yaitu keuangan, pelanggan, proses bisnis internal, serta pembelajaran dan pertumbuhan. Penerapan ukuran-ukuran pada keempat perspektif ini memindahkan evaluasi dari elemen kontrol menjadi suatu alat yang menempatkan strategi menjadi tindakan (Kaplan dan Norton, 2001). 
Strategi map menggambarkan bagaimana memanfaatkan intangible assets dalam proses penciptaan nilai sejalan dengan strategi yang ada. Dengan kata lain, apabila suatu perusahaan menginginkan balanced scorecard yang baik (measuring and actioning), maka perusahaan harus mempunyai strategy map yang baik pula (describing). Strategy map adalah gambaran yang menghubungkan antara faktor-faktor yang ada pada critical success factor suatu organisasi, juga menggambarkan strategi, tujuan, dan pengukuran (Kaplan and Norton, 2004).

Penerapan strategy map dan balanced scorecard diharapkan dapat membantu manajemen $\mathrm{Ru}-$ mah Sakit Bersalin X dalam menghadapi persaingan bisnis pelayanan kesehatan pada masa mendatang melalui penerjemahan visi, misi, dan strategi ke dalam aksi dan tindakan operasional dengan memanfaatkan indikator finansial dan non-finansial perusahaan, khususnya pada divisi purchase. Di mana pada divisi ini yang merupakan bagian dari tata usaha dalam struktur organisasi perusahaan bertanggung jawab terhadap segala bentuk pembelian, perencanaan dan pelaporan perlengkapan, peralatan, dan obat-obatan yang menunjang operasional perusahaan dan sangat erat kaitannya dengan operational expense yang sering kali tidak sesuai dengan perencanaan.

\section{PERUMUSAN MASALAH}

Rumah Sakit Bersalin X saat ini sedang melakukan pengembangan usaha yang bertujuan agar paradigma family company tidak terus melekat pada perusahaan sehingga diperlukan performance management system sebagai tools pengelolaan manajemen secara profesional. Berdasarkan uraian pada latar belakang maka disusun rumusan masalah penelitian sebagai berikut: Bagaimana rancangan Performance Man- agement System sebagai Tools Pengelolaan Manajemen secara Profesional Divisi Purchase Rumah Sakit Bersalin X?

\section{TINJAUAN PUSTAKA}

Kinerja

Bernardin dan Rusel dalam Rucky (2002) memberikan definisi tentang performance sebagai berikut. "Performance is defined as the record of outcomes produced on a specified job function or activity during a specified time period" yang berarti prestasi adalah catatan tentang hasil-hasil yang diperoleh dari fungsi-fungsi pekerjaan tertentu atau kegiatan tertentu selama kurun waktu tertentu.

Performance management adalah proses yang digunakan untuk identify, encourage, measure, evaluate, improve, dan reward kinerja karyawan (Aguinis, 2006). Pendapat lain mengatakan bahwa performance management adalah sebuah tatanan pengukuran berdasarkan aturan dan prosedur tertentu untuk mencakup, mengompilasi, mempresentasikan, dan mengomunikasikan data dalam sebuah kombinasi yang mencerminkan kunci kinerja dan karakteristik proses terpilih yang cukup efektif yang memungkinkan analisis intelektual sebagai panduan untuk mengambil tindakan yang diperlukan (Ljungberg, 1994).

\section{Visi, Misi, dan Strategi}

Setiap organisasi mempunyai tujuan yang ingin dicapai, baik tujuan jangka pendek maupun jangka panjang. Dalam menentukan tujuan, setiap organisasi terkait dengan visi, misi, dan strategi yang telah ditetapkan untuk tetap bertahan di pasar dan memenangkan persaingan. Visi adalah suatu pandangan jauh ke depan tentang organisasi atau impian yang ingin dicapai 
(Luis, 2009). Visi harus sederhana, praktis, realistis, memberikan tantangan dan diharapkan memotivasi karyawan untuk meningkatkan kinerjanya. Misi adalah tujuan dan alasan keberadaan suatu organisasi. Misi menyatakan apa yang harus dilakukan dan mengapa organisasi itu ada (Luis, 2009). Pernyataan misi adalah suatu usaha formal untuk memperjelas apa yang dikehendaki oleh pemilik perusahaan ketika mendirikan perusahaan dan menjadi pegangan untuk mengendalikan selanjutnya. Strategi didefinisikan sebagai teori dari suatu perusahaan mengenai bagaimana untuk bisa sukses berkompetisi di pasar (Barney, 2002). Setiap strategi bisnis memiliki competitive strategy. Menurut Porter (1996), competitive strategy is performing different activities from rivals, or performing similar activities in different ways: cost leadership, differentiation, and focus, dengan penjelasan sebagai berikut.

\section{Cost leadership}

Strategi yang mengarah pada biaya yang murah sehingga mendapatkan harga jual yang murah, orientasi pasar terhadap harga.

\section{Differentiation}

Strategi yang mengarah pada keunikan produk/jasa tanpa memperhatikan faktor harga yang dapat dicapai melalui kualitas, pelayanan, fitur, dan lain-lain, orientasi pasar terhadap premium produk/jasa.

\section{Focus}

Strategi ini dilakukan oleh perusahaan dengan cara memfokuskan produknya kepada kelompok pembeli, segmen lini produk atau pasar geografis tertentu.

\section{Balanced Scorecard}

Balanced scorecard pertama kali diperkenalkan oleh Kaplan dan Norton pada Harvard Business Review, Edisi Januari-Februari Tahun
1996, yang membahas kerangka berpikir komprehensif mengenai ukuran kinerja untuk mengimplementasikan strategi. Balanced scorecard merupakan model yang populer di dunia maupun di Indonesia baik di kalangan akademisi dan praktisi. Balanced scorecard memiliki kerangka kerja yang jelas bagaimana strategi dapat mendistribusikan secara terperinci sampai KPI (key performance indicator) (Prasetiyatno, Hidayat dan Utami, 2011 dalam Vanany, 2009).

Balanced scorecard merupakan seperangkat instrumen yang diperlukan organisasi untuk mengelola organisasi menuju keberhasilan persaingan di masa depan. Di mana tujuan strategi dan indikator kinerja diturunkan dari visi, misi, dan strategi, tujuan dan indikator tersebut merupakan cara pandang kinerja organisasi berdasarkan empat perspektif yaitu: financial, customer, internal business process, dan learning o growth. Balanced scorecard, lebih ditekankan pada semua indikator baik finansial dan non-finansial, di mana keduanya berfungsi sebagai bagian sistem informasi bagi karyawan (Vanany, 2009).

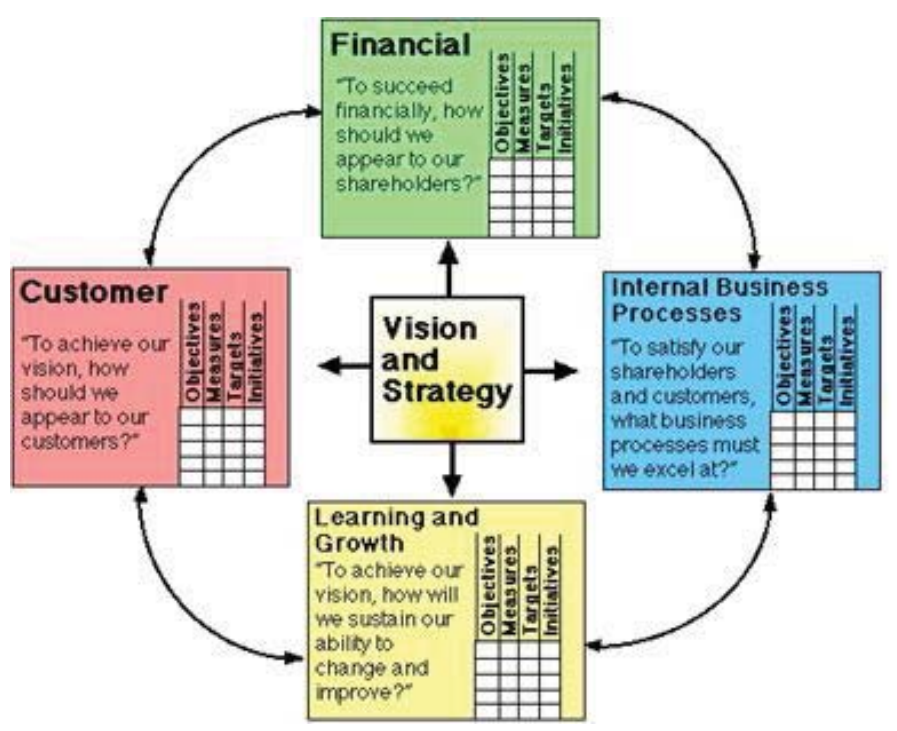

Gambar 1 Balance Scorecard Diadaptasi dari Robert S. Kaplan dan David P. Norton, Menggunakan Balanced Scorecard sebagai Sistem Manajemen Strategis, Harvard Business Review (Januari-Februari 1996) 
Perspektif Pembelajaran \& Pertumbuhan (Learning \& Growth Perspective)

Mengembangkan pengukuran yang bertujuan untuk mendorong organisasi agar berjalan dan tumbuh dengan menyediakan infrastruktur yang mendukung pencapaian ketiga perspektif lainnya, dengan memperhatikan faktor sebagai berikut.

1. Kepuasan karyawan: keterlibatan dalam pengambilan keputusan, pengakuan, akses untuk memperoleh informasi, dorongan untuk melakukan kreativitas dan inisiatif, serta dukungan dari atasan, kesempatan untuk meningkatkan knowledge dan skill.

2. Kemampuan sistem informasi: informasi yang dibutuhkan mudah didapatkan, tepat, dan tidak memerlukan waktu lama untuk mendapat informasi tersebut (Vanany, 2009).

\section{Perspektif Proses Bisnis (Internal Business Pro- cess Perspective)}

Perspektif ini mengacu pada proses bisnis internal. Proses bisnis internal mempunyai nilainilai yang diinginkan konsumen dan dapat memberikan pengembalian yang diharapkan oleh para pemegang saham yang meliputi inovasi, proses operasi, dan proses penyampaian produk atau jasa pelanggan (Vanany, 2009).

\section{Perspektif Pelanggan}

Masa lalu seringkali perusahaan mengonsentrasikan diri pada kemampuan internal dan kurang memperhatikan kebutuhan konsumen. Sekarang strategi perusahaan telah bergeser fokusnya dari internal ke eksternal. Jika suatu unit bisnis ingin mencapai kinerja keuangan yang superior dalam jangka panjang, mereka harus menciptakan dan menyajikan suatu produk atau jasa yang bernilai dari biaya perolehannya. Suatu produk akan semakin bernilai apabila kinerjanya semakin mendekati atau bahkan melebihi dari apa yang diharapkan dan dipersepsikan konsumen (Sundari, 2012). Tolok ukur kinerja pelanggan dibagi menjadi dua kelompok berikut.

1. Kelompok inti: pangsa pasar, tingkat perolehan para pelanggan baru, kemampuan mempertahankan para pelanggan lama, tingkat kepuasan pelanggan, dan tingkat profitabilitas pelanggan.

2. Kelompok penunjang: atribut produk (fungsi, harga, dan mutu), hubungan dengan pelanggan, dan citra serta reputasi perusahaan/ organisasi beserta produk-produknya (Vanany, 2009).

\section{Perspektif Keuangan}

Perspektif keuangan menjadi perhatian dalam balance scorecard karena ukuran keuangan merupakan konsekuensi ekonomi yang terjadi akibat keputusan dan kebijakan. Tujuan pencapaian kinerja keuangan yang baik merupakan fokus dari tujuan yang ada dalam tiga perspektif lainnya (customer, internal business process, dan learning \& growth). Sasaran perspektif keuangan dibedakan pada masing-masing tahap dalam siklus bisnis sebagai berikut.

1. Growth (tumbuh berkembang pertumbuhan)

Pada tahapan ini pertumbuhan terfokus pada produk yang meningkat secara signifikan, dengan demikian strategi dan peningkatan perspektif finansial dapat difokuskan pada pertumbuhan penerimaan penghasilan dan atau keuntungan yang positif yang didukung peningkatan pangsa pasar dan peningkatan penjualan. 
2. Sustain (bertahan $\sim$ keberlanjutan)

Pada tahapan ini mengidentifikasikan bahwa produk yang ada, memiliki produk yang tumbuh stabil sehingga strategi dan pengukuran dalam perspektif finansial dapat difokuskan pada pertumbuhan pendapatan operasional, pengembalian tingkat investasi, dan peningkatan keuntungan kotor.

3. Harvest (panen $\sim$ kematangan).

Pada tahapan ini, produksi produk sudah tidak seperti saat awal berkembang atau saat posisi growth, dengan demikian fokus strategi dan pengukuran keuangan dapat difokuskan pada pengelolaan arus kas, nilai tambah kas (Vanany, 2009).

\section{METODE PENELITIAN}

Pendekatan penelitian yang digunakan dalam penelitian ini adalah penelitian kualitatif. Penelitian deskriptif adalah suatu metode yang digunakan untuk menggambarkan atau menganalisis suatu hasil penelitian tetapi tidak digunakan untuk membuat kesimpulan yang lebih luas. Jadi, penelitian deskriptif merupakan penelitian yang berusaha mendeskripsikan suatu gejala, peristiwa yang terjadi pada saat sekarang atau masalah aktual.

\section{Lokasi Penelitian dan Unit Analisis}

Lokasi penelitian ini dilakukan di Rumah Sakit Bersalin X yang bertempat di Pacitan.

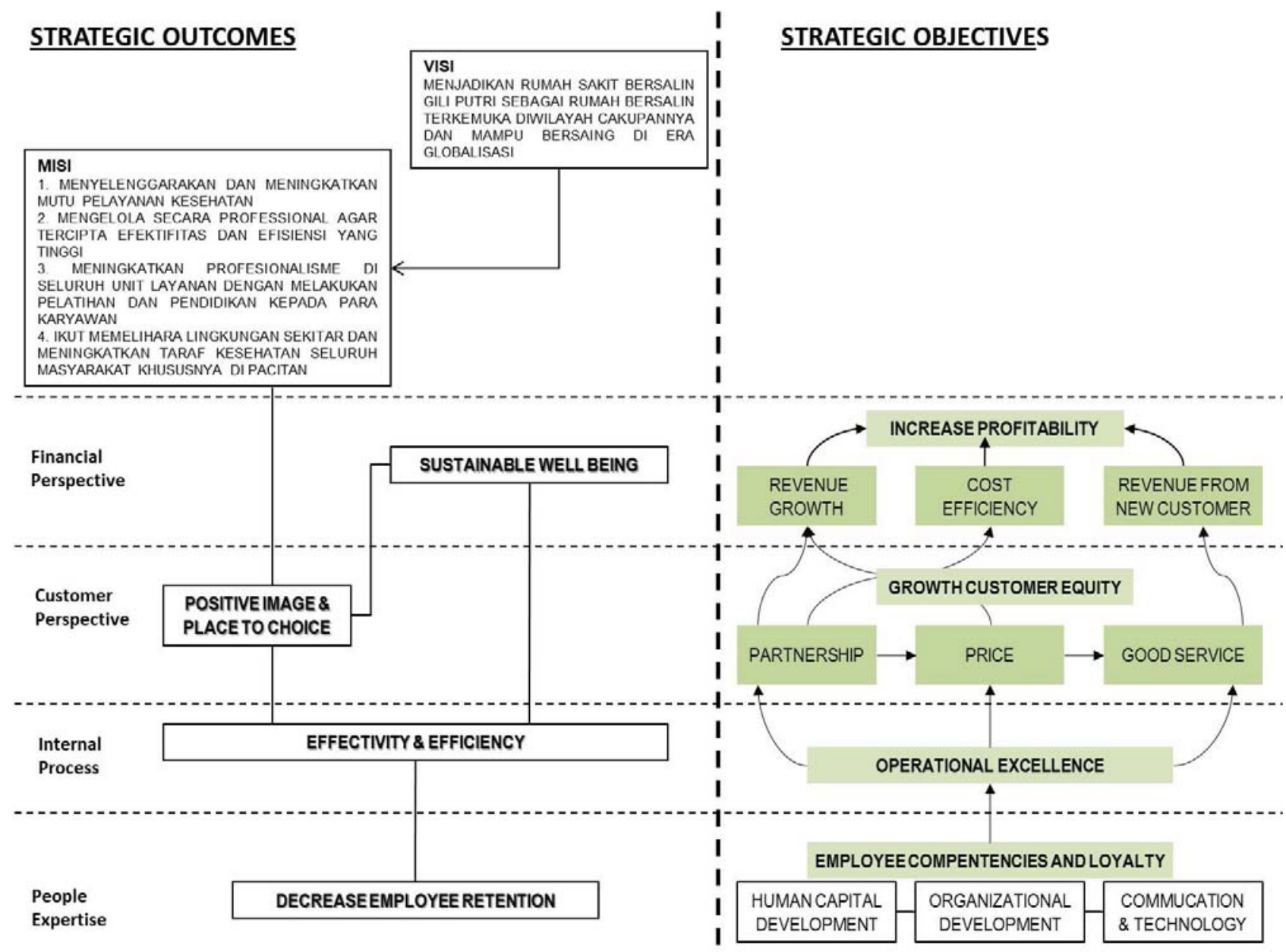

Gambar 2 Corporate Outcomes dan Strategy Objectives Rumah Sakit Bersalin X di Pacitan 
Pemilihan tempat penelitian ini dengan pertimbangan mempermudah jangkauan informasi dan pengumpulan data saat melakukan wawancara. Unit analisis yang akan digunakan sebagai objek penelitian adalah penyusunan strategy maps dan balanced scorecard.

\section{Jenis dan Sumber Data}

Jenis penelitian ini adalah eksploratoris yakni dengan melakukan peninjauan atau observasi keadaan internal dan eksternal Rumah Sakit Bersalin X di Pacitan. Kegiatan ini berguna untuk mendapatkan gambaran secara sistematis mengenai fakta pada objek penelitian sesuai dengan pokok permasalahan yang diteliti, kemu- dian membuat perbandingan dan analisis dengan teori yang digunakan.

\section{ANALISIS DAN PEMBAHASAN HASIL PENE- LITIAN}

\section{Balance Scorecard dan Strategi Map}

Manajemen Rumah Sakit Bersalin X menyadari bahwa salah satu langkah pengelolaan unit usaha yang profesional adalah dengan penetapan strategi perusahaan yang didukung dan diaplikasikan oleh semua jenjang dalam perusahaan dan dapat diukur agar dapat berfungsi secara efektif untuk mencapai visi perusahaan. Untuk itu diperlukan suatu alat yang dapat mengukur sistem manajemen dan kinerja perusahaan yaitu dengan

\section{STRATEGI MAP RSB X PACITAN}

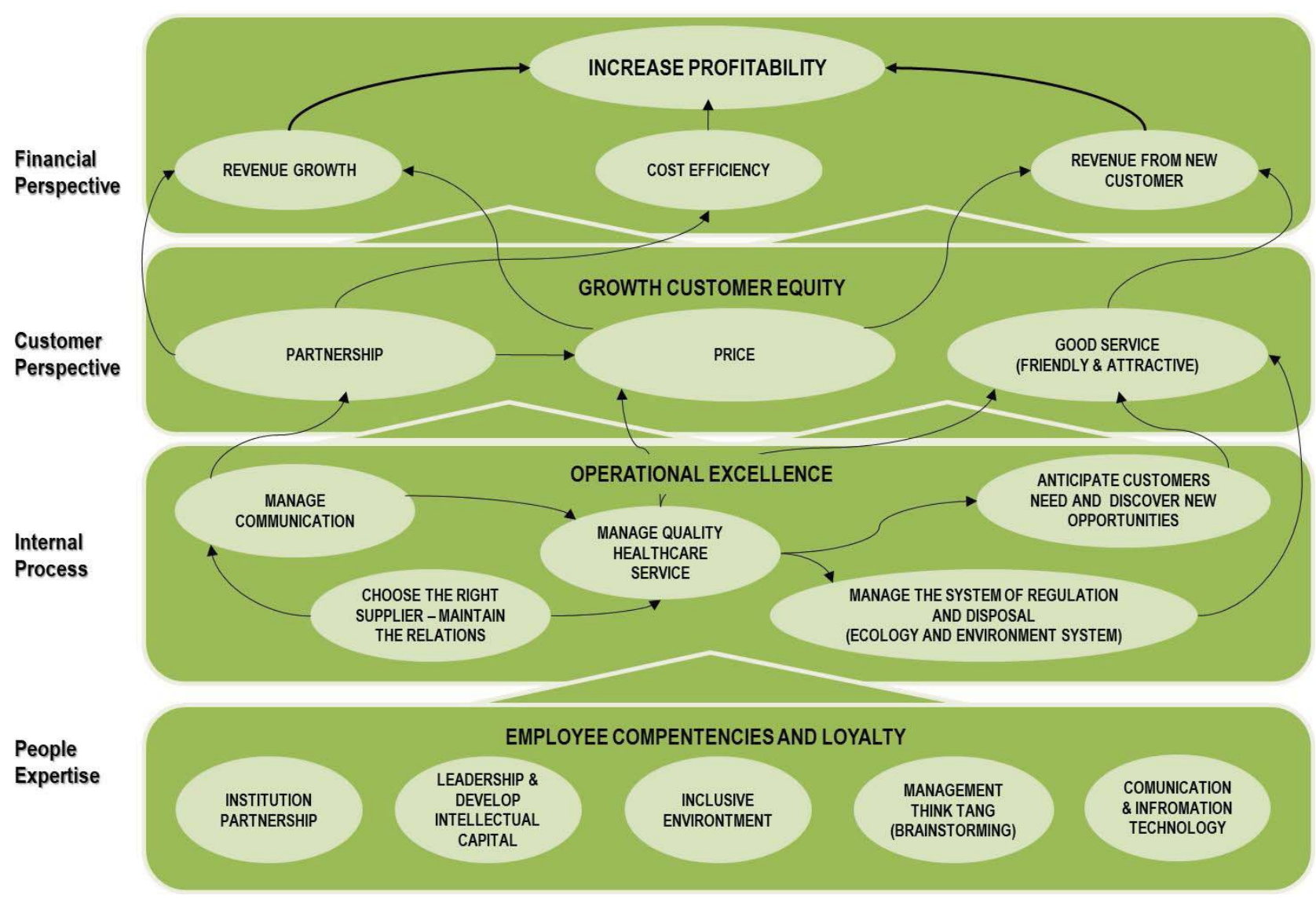

Gambar 3 Strategi Map RSB X Pacitan 
menentukan key performance indicator untuk memudahkan pengukuran melalui BSC framework dan strategi maps.

Pada gambar strategy maps di atas, untuk memaksimalkan operasional perusahaan dalam rangka mencapai visi perusahaan, manajemen Rumah Sakit Bersalin X Pacitan menjalankan high contacts business strategy yaitu dengan merekrut tenaga kerja yang memiliki kompetensi, pengetahuan, keterampilan, dan kemampuan sebagai core employee business perusahaan yang tidak dapat di kesampingkan, karena tenaga kerja ini sebagai eksekutor dalam perusahaan dan sangat perlu dipertahankan. Oleh karena itu, terlihat pada perspektif learning and growth, perusahaan lebih memilih 'people expertise', yaitu dengan memilih tenaga kerja yang memiliki keahlian yang disesuaikan setiap divisi dalam perusahaan. People expertise disiapkan sebagai eksekutor strategi dan rencana perusahaan yang terlihat dalam internal process. Dominasi pada people expertise ini yang menggerakkan 'operational excellence' yang diharapkan dapat meningkatkan customer equity dan dengan begitu akan memengaruhi pendapatan dan profitabilitas perusahaan secara keseluruhan.

Dengan investasi tenaga kerja yang ahli dalam bidangnya dan meningkatkan pengembangan human capital jangka panjang, maka secara tidak langsung akan memaksimalkan proses operasional perusahaan secara keseluruhan.

Tata usaha merupakan salah satu divisi yang menjalankan proses operasional perusahaan, yang memiliki peran dalam kegiatan perenca-

\section{STRATEGI OBJECTIVE PERUSAHAAN YANG BERHUBUNGAN DENGAN DIVISI PURCHASE}

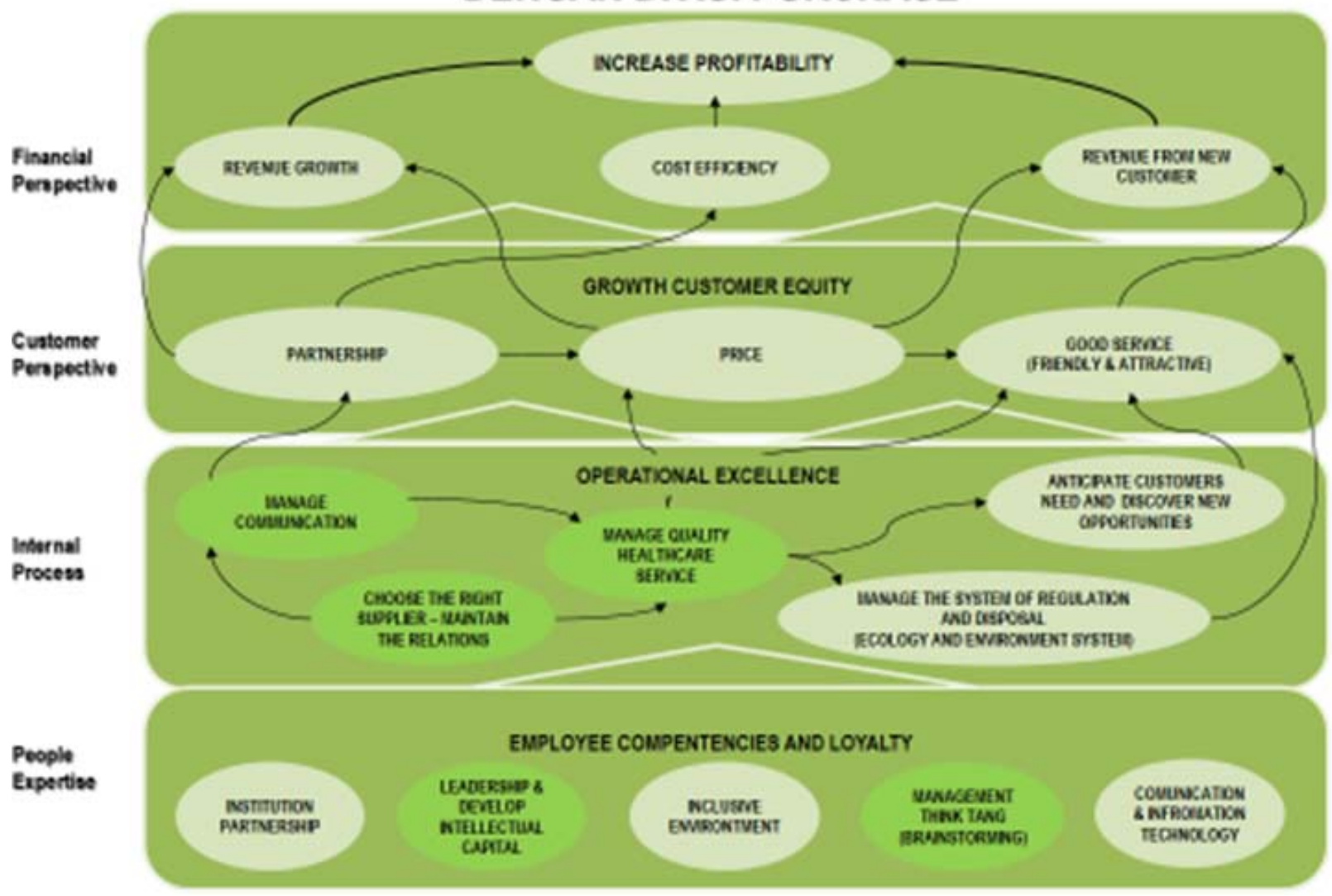

Gambar 4 Strategi Objektif yang Berhubungan dengan Divisi Purchase 
naan, pembelian serta pelaporan yang berkaitan dengan perlengkapan, peralatan, dan obat-obatan Rumah Sakit Bersalin Gili Putri yang menunjang internal proses, berikut ini merupakan gambar penurunan strategi objektif perusahaan yang berhubungan dengan divisi purchase.

Berdasarkan Gambar 4, strategi objective perusahaan yang berkaitan dengan purchase (tata usaha) adalah sebagai berikut.

1. Internal process

a. Choose the right supplier - maintain the relation

b. Manage a good communication (friendly os attractive) c. Manage quality healthcare service

2. People expertise

a. Leadership \& develop intellectual capital

b. Management think tang (brainstorming)

Berdasarkan penurunan strategi map di atas maka diturunkan kembali kemudian direncanakan tahapan inisiatif setiap strategi agar tercapai strategi objektif setiap perspektif.

Berdasarkan Gambar 5 dapat dikelompokkan key performance indicator berdasarkan strategi objektif perusahaan setelah diturunkan. Berikut ini merupakan tabel key performance indicator Divisi Purchase RSB X Pacitan.

\section{SKEMA PENURUNAN STRATEGI OBJECTIVE PERUSAHAAN KE DIVISI PURCHASE}

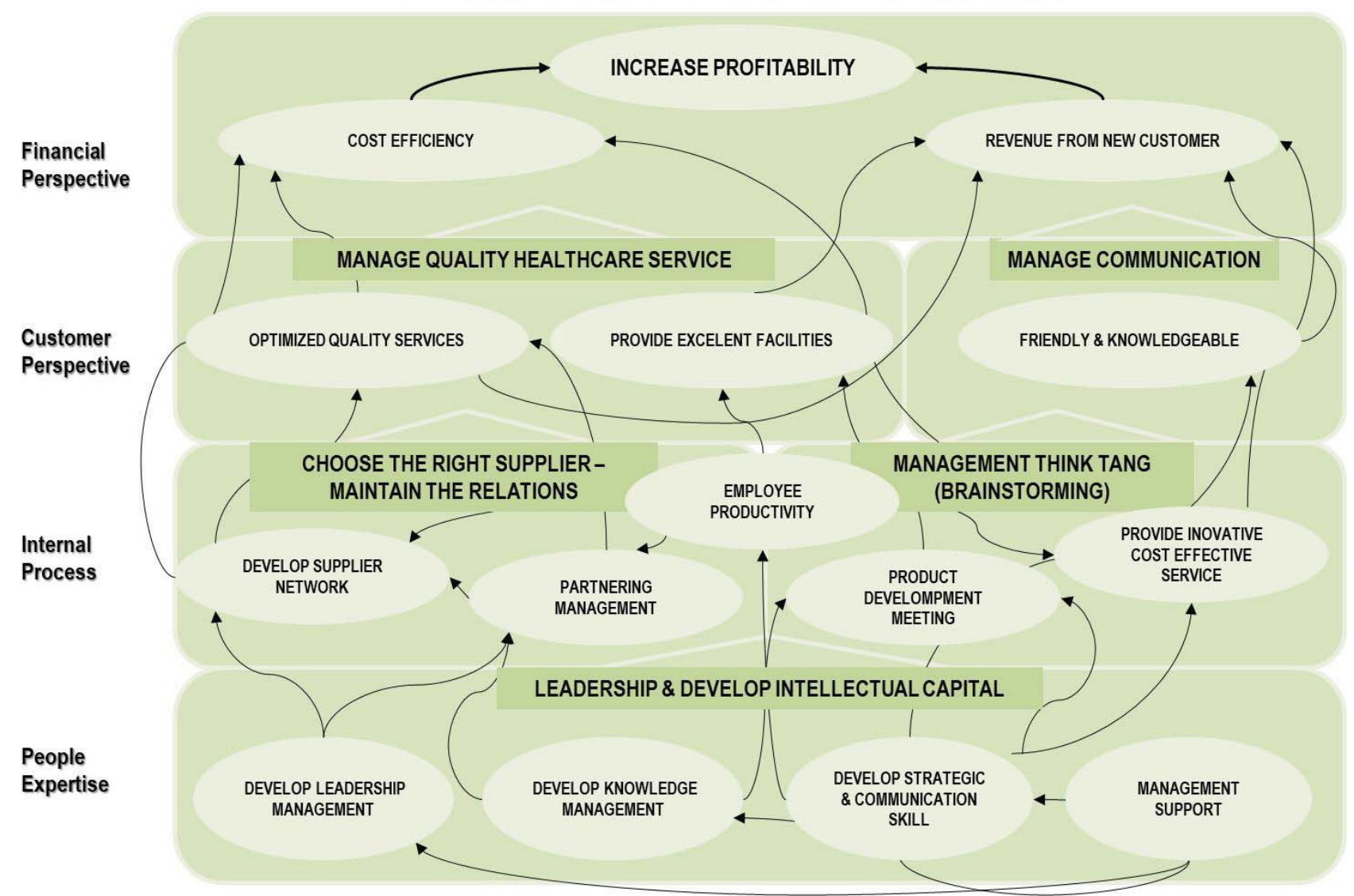

Gambar 5 Strategi Map Penurunan Strategi Objektif ke Divisi Purchase 
Tabel 1 Key Performance Indicator Divisi Purchase RSB Pacitan

\begin{tabular}{|c|c|c|c|}
\hline PERSPECTIVE & OUTCOMES & OBJECTIVES & $K P I$ \\
\hline $\begin{array}{c}\text { Financial } \\
\text { Perspective }\end{array}$ & $\begin{array}{c}\text { Increase } \\
\text { Profitability }\end{array}$ & $\begin{array}{l}\text { Increase Profitability } \\
\text { - Cost Efficiency } \\
\text { - Revenue from new Customer }\end{array}$ & $\begin{array}{l}\text { - Plan vs. Actual Operating Expenses } \\
\text { (cost saving \%) } \\
\text { - Service's New Customer } \\
\text { Profitability (\%) }\end{array}$ \\
\hline $\begin{array}{l}\text { Customer } \\
\text { Perspective }\end{array}$ & $\begin{array}{l}\text { Growth } \\
\text { Customer } \\
\text { Equity }\end{array}$ & $\begin{array}{l}\text { Manage Quality Healthcare } \\
\text { Service } \\
\text { - Optimized Quality Service } \\
\text { - Provide Excellence Facilities } \\
\text { Manage Communication } \\
\text { - Friendly \& Knowledgeable }\end{array}$ & $\begin{array}{l}\text { - Customer Satisfaction Index } \\
\text { - Number customer complaint } \\
\text { - Number customer know our } \\
\text { product/service knowledge }\end{array}$ \\
\hline Internal Process & $\begin{array}{l}\text { Operational } \\
\text { Excellence }\end{array}$ & $\begin{array}{l}\text { Choose The Right Supplier - } \\
\text { Maintain The Relation } \\
\text { - Develop Supplier Network } \\
\text { - Partnering Management } \\
\text { Management Think Tang } \\
\text { (Brainstorming) } \\
\text { - Product Development Meeting } \\
\text { - Provide Innovative Cost } \\
\text { Effective Service } \\
\text { Employee productivity }\end{array}$ & $\begin{array}{l}\text { - Perfect Order (\%) / Percent Of } \\
\text { Defect } \\
\text { - Number of suppliers providing } \\
\text { services directly } \\
\text { - Gain sharing agreement (\$) } \\
\text { - Number of innovation services } \\
\text { - Activity Based Costing } \\
\text { - Absenteeism } \\
\text { - Number of best project } \\
\text { implemented }\end{array}$ \\
\hline People Expertise & $\begin{array}{l}\text { Employee } \\
\text { Competencies } \\
\text { and Loyalty }\end{array}$ & $\begin{array}{l}\text { Leadership \& Develop } \\
\text { Intellectual Capital } \\
\text { - Develop Leadership } \\
\text { Management } \\
\text { - Develop Knowledge } \\
\text { Management } \\
\text { - Develop Communication And } \\
\text { Strategic Skill } \\
\text { - Management Support }\end{array}$ & $\begin{array}{l}\text { - Percent Recruitment Employee } \\
\text { (Appropriate With Core Business) } \\
\text { - Percent Using Knowledge-Sharing } \\
\text { Channel } \\
\text { - Employee Survey Index } \\
\text { - Percent Of Employee Who Obtain } \\
\text { Immediate Feedback After Having } \\
\text { Training } \\
\text { - } 360 \text { 'Performance Management } \\
\text { Index }\end{array}$ \\
\hline
\end{tabular}

\section{SIMPULAN DAN SARAN}

Melihat perkembangan dan persaingan global diperlukan perubahan dalam pola pengelolaan manajemennya yang berorientasi pada pengguna jasa. Rumah sakit sebagai perusahaan harus berpikir profit tanpa meninggalkan fungsi sosialnya, dan untuk mencapai sasaran yang dikehendaki dalam usaha mencapai profit, usaha perumahsakitan harus meningkatkan kualitas pelayanannya.
Rumah Sakit Bersalin X adalah rumah sakit swasta yang berdiri tanpa visi dan misi tertulis dari pendirinya. Rumah sakit ini merupakan perusahaan keluarga yang berdiri sebagai Klinik Bersalin dan pada tahun 2010 berubah badan usaha menjadi Rumah Sakit Bersalin. Dengan adanya perkembangan globalisasi yang cukup pesat dari tahun ke tahun menyebabkan pihak manajemen rumah sakit harus mulai merencanakan strategi yang bersifat jangka panjang dan berkelanjutan. Untuk itu, pihak manajemen mu- 
lai menuliskan kembali apa yang menjadi harapan perusahaan secara tertulis dan mengomunikasikan secara menyeluruh ke semua divisi yang ada di dalam rumah sakit tersebut.

Balance scorecard dan strategy map digunakan sebagai media dalam memudahkan komunikasi top-down management, sebagaimana yang diketahui bahwa dengan menerapkan strategi ini apa yang diharapkan manajemen dapat goal setting, mudah dalam proses monitoring dan evaluasi sehingga continuously improvement tercipta. Menerapkan performance management system diharapkan akan memudahkan dalam mengukur kinerja perusahaan secara keseluruhan dan menentukan action plan tiap divisi sehingga memudahkan manajemen bertindak cepat untuk menangani permasalahan yang sedang terjadi. Seperti yang sering kali terjadi pada divisi purchase dalam hal pembelian perlengkapan, peralatan dan obat-obatan sering kali tidak sesuai dengan perencanaan, mengingat peralatan dan obat-obatan tidak memiliki standard cost yang pasti (harga fluktuatif). Dengan framework balance scorecard, strategy maps dan performance review akan memberikan kemudahan manajemen untuk memonitor dan mengevaluasi serta menciptakan hubungan kerja yang bersinergi.

\section{DAFTAR RUJUKAN}

Aguinis, Herman. 2006. Performance Management, Second Edition. Pearson International.

Ambarwati, Sri D.A. 2002. Managing Productive Performance Appraisal: Sebuah Upaya Menjawab Kebutuhan Penilaian Kinerja Karyawan Yang Bebas KKN. Jurnal Siasat Bisnis, No. 7, Vol. 1, Hal. 93-111. Fakultas Ekonomi Universitas Pembangunan Nasional "Veteran".
Aprilia, Rora. 2016. Pengaruh Good Corporate Governance, Budaya Organisasi dan Pengendalian Intern terhadap Kinerja Organisasi dengan Akuntabilitas Publik sebagai Variabel Intervening (Survey Terhadap Rumah Sakit di Kota Padang). JOM Fekon, Vol. 3, No. 1, Hal. 564-579.

Barney, J. B. 2002. Gaining and Sustaining Competitive Advantage (Second ed.). Prentice Hall.

Beals, Reginald M. 2000. Competing Effectively: Environmental Scanning, Competitive Strategy and Organizational Performance in Small Manufacturing Firms. Journal of Small Business Management, Hal. 27-45.

http://www.pacitankab.go.id

Jufrizen dan Radiman. 2010. Efektivitas Budaya Organisasi Pelayanan Publik (Studi Kasus di Beberapa Rumah Sakit Pemerintah di Kota Medan). Jurnal Riset Akuntansi dan Bisnis, Vol. 10, No. 1, Hal. 44-67.

Kaplan, R.S. and D.P. Norton, 1996. Translating Strategic into Action - The Balanced Scorecard. Boston, Massachusetts: Harvard Business School Press.

Kaplan, R.S., dan Norton, David P. 2004. Strategy Maps, Converting Intangible Assets into Tangible Outcomes. Boston, Massachusetts: Harvard Business School Press.

Kaplan, Robert S. and David P. Norton. 2001. Balanced Scorecard Menerapkan Strategi Menjadi Aksi. Jakarta: Penerbit Erlangga. Laksono, Ismawan Nur. 2008. Analisis Kepuasan dan Hubungannya dengan Loyalitas Pasien Rawat Inap di Rumah Sakit Dedi Jaya Kabupaten Brebes. Semarang: Program Pascasarjana Universitas Diponegoro.

Ljungberg, A. 1994. A Measurement of Service and Quality in the Order Process. Unpublished theses Lund University Belgium. 
Luis, Suwardi. 2009. Step by Step in Developing Vision, Mission, and Value Statements. Jakarta: Gramedia Pustaka Utama.

Muluk, Khairul. 2007. Budaya Organisasi Pelayanan Publik (Kasus pada Rumah Sakit X di Malang). Jurnal Akuntansi.

Mwita, John I. 2000. Performance Management Model A Systems-Based Approach to Public Service Quality. The International Journal of Public Sector Management, Vol. 13, No. 1, Hal. 19-37.

Sundari, Sri. Hubungan Balance Scorecard sebagai Pengukuran Kinerja pada Critical Success Factors Perusahaan. Diunduh melalui http://repository.unhas.ac.id/bitstream/ handle.
S. Ruky. A. 2002. Sistem Manajemen Kinerja: Performance Management System, Panduan Praktis untuk Merancang dan Meraih Kinerja Prima. Jakarta: PT Gramedia Pustaka Utama.

Vanany, Iwan dan Dian Tanukhidah. 2004. Perancangan dan Implementasi Sistem Pengukuran Kinerja dengan Metode Performance Prism. Jurnal Teknik Industri, Vol. 6, No. 2, Hal. 148-145.

Vanany, Iwan. 2009. Performance Measurement: Model dan Aplikasi, Cetakan ke-2 Revisi. Surabaya: ITS Press. 